\title{
High Proton Conductive Sulfonated Graph Copolyimide Membranes Containing Chemically Stable Naphthalene Moieties
}

\author{
K. Yamazaki ${ }^{1}$, M. Tanalka ${ }^{2} \&$ H. Kawakami ${ }^{3 *}$ \\ ${ }^{1,2 \& 3}$ Department of Applied Chemistry, Tokyo Metropolitan University, Hachioji, Tokyo, 192-039, Japan
}

\begin{abstract}
Syntheses, proton conductivity, gas permeability properties, and membrane stabilities of novel sulfonated graft copolyimides were investigated. The sulfonated graft copolyimide membrane showed significantly high proton conductivity $\left(0.96 \mathrm{~S} / \mathrm{cm}\right.$ at $90^{\circ} \mathrm{C}$ and $98 \% \mathrm{RH}$, more than 6 times that of Nafion), suggesting that the protons in the sulfonated grait copolyimide membranes were efficiently transported. The oxidative stability of the novel sulfonated graft copolyimide was higher than that of the conventional graft copolyimide because of their polymer structures containing chemically stable naphthalene moieties and non-sulfonated polymer main-chain. Furthermore, the oxygen permeability of the membrane was approximately one-fourth the value of Nafion and had a very excellent gas barrier property. We demonstrated that the graft copolymer membrane could realize high proton conductivity and low gas permeability to have potential applications for use in fuel cells.
\end{abstract}

Keywords: Fuel cell, polymer electrolyte membrane, proton conductivity, gas pearmeability

\subsection{INTRODUCTION}

Polymer electrolyte fuel cells (PEFCs) have attracted considerable attention as alternative energy source because of its high energy efficiency and no emissions of pollutants. ${ }^{1}$ However, improvement in performance and durability, and reduction of cost are needed before the practical applications. Proton-conducting polymer electrolyte membranes are one of the key components in PEFCs, and are required various properties including high proton conductivity, high chemical and physical stability, and low gas permeability. ${ }^{2-4}$ Perfluorinated sulfonic acid (PSFA) ionomers, such as Nafion( $($, have been the most widely used for the polymer electrolyte membrane because of their high proton

\footnotetext{
* Corresponding to: H. Kawakami (email: kawakamihịroyoshi@tmu.ac.jp)
}

conductivity. The PFSA membranes, however, have several issues on low thermal stability and high gas permeability as well as environmental inadaptability and production cost. Therefore, there has been a great demand for non-fluorinated alternative proton conductive membranes. Recently, much effort has directed to the development of aromatic hydrocarbon polymer electrolyte membranes, ${ }^{5-9}$

Sulfonated polyimides (SPIs) are one of the promising candidates due to their high chemical and thermal stabilities and good mechanical strength. ${ }^{10-19}$ Especially, sulfonated polyimide containing 1,4,5,8-naphthalene diimide, which is composed of four six-membered rings, have been proposed to be promising materials for a proton exchange membrane, because the polyimides exhibit excellent chemical and thermal stabilities compared to those of five-membered ring 
polyimides. ${ }^{11,12,16,18}$ Besides such high chemical and thermal stabilities and good mechanical strength, low gas permeability is also an attracting property. However, random sulfonated polyimides do not necessarily show high proton conductivity due to the lack of ordered ionic channels for the effective proton transport. Various approaches have been investigated to form efficient ionic channels for enhancing the proton conductivity. One of the promising approaches is the syntheses of sulfonated block copolymers and/or graft copolymers to induce a hydrophilic-hydrophobic microphase separation for the formation of efficient proton transport channels. ${ }^{7-9,17-19} \mathrm{We}$ have previously reported synthesis and properties of sulfonated block copolyimides ${ }^{18}$ and sulfonated graft copolyimides. ${ }^{19}$ Although they showed higher proton conductivities than the corresponding random sulfonated copolymers, ${ }^{10-}$ 16 their oxidative stability and gas barrier properties are not sufficient to realize fuel cell electrolytes using the polymers. Hydrogen and oxygen crossovers through the membrane are an undesirable diffusion, because their crossovers lead to at least three problems: fuel efficiency reduction, anode and cathode potential depression, and formation of reactive oxygen species. $^{20-22}$ Therefore, novel sulfonated polymer membranes bearing high proton conductivity and low gas permeability are desired for practical polymer electrolyte membranes.

Here we describe the syntheses and characteristics of a series of sulfonated graft copolyimides containing six-membered ring naphthalene moieties. Proton conductivity, water uptake, oxidative stability, and gas permeability of the novel sulfonated graft copolyimides were investigated. We focused mainly on the influence of the IECs and polymer structures of the sulfonated graft copolyimides on the proton conductivity and membrane stability.

\subsection{EXPERIMENTAL}

\subsection{Materials}

1,4,5,8-Naphthalene tetracarboxylic dianhydride (NTDA) was purchased from Sigma-Aldrich Co.
(St. Louis, MO, USA) and was used as received. 4,4'-Diamino-biphenyl 2,2'-disulfonic acid (BDSA) was purchased from Tokyo Kasei Co. (Tokyo, Japan) and was purified by dissolution in a triethylamine aqueous solution and precipitated in $1 \mathrm{~N} \mathrm{H}_{2} \mathrm{SO}_{4}$, and then BDSA was dried in a vacuum oven at $70^{\circ} \mathrm{C}$ for $12 \mathrm{hr}$. 2,2-bis[4-(4aminophenoxy)phenyl] hexafluoropropane (APPF) was purchased from Tokyo Kasei Co. (Tokyo, Japan) and was recrystalized from ethanol. 3,5-Diaminobenzoic acid (DABA) was purchased from Tokyo Kasei Co. (Tokyo, Japan) and was used as received. All other chemicals were purchased from Kanto Chemical Co. (Tokyo, Japan) and were used as received. Nafion ${ }^{(117}$ was used in this study as the control membrane. The membrane was obtained from the DuPont Co. Ltd. (Tokyo, Japan).

\subsection{Syntheses of Sulfonated Graft Copolyimide}

A novel sulfonated graft polyimide was synthesized as shown in Scheme 1. The random copolyimide NTDA-APPF- $r$-DABA as the main-chain polymer was prepared using the similar method that we previously reported. ${ }^{10}$ Equivalent moles of APPF and DABA monomers were dissolved together with 2 mol equiv of NTDA in dry $m$-cresol. After adding benzoic acid catalyst, the solution was gently heated with stirring at $70^{\circ} \mathrm{C}$ for $4 \mathrm{hr}$ and then refluxed with stirring for $24 \mathrm{hr}$. NTDA-APPF$r$-DABA polyimide was precipitated in a mixture of methanol and water (6:4 volume ratio). Subsequently, the polyimide was dried in a vacuum oven at $150^{\circ} \mathrm{C}$ for $15 \mathrm{hr}$. The block copolyimide NTDA-APPF- $b$-DABA was prepared by similar procedure of the NTDA-APPF- $r$-DABA except the NTDA-APPF segment and NTDA-DABA segment were prepared separately and combined after obtaining both segments.

The sulfonated graft copolyimides, NTDAAPPF- $r$-DABA-g-NTDA-BDSA, were synthesized from the NTDA-APPF- $r$-DABA as the main-chain polymer and sulfonated diamino-terminated NTDA-BDSA as the side-chain polymer. The diamino-terminated polyimides, NTDA-BDSA, were prepared by the reaction of NTDA (1 eq.) 
and the small excess amount of BDSA (1.02 eq.) in $m$-cresol in the presence of triethylamine at $120^{\circ} \mathrm{C}$ for $24 \mathrm{hr}^{10}$ Subsequently, NTDA-APPF- $r$ DABA, triphenylphosphine, and pyridine were added in the NTDA-BDSA solution. The mixture was stirred at $120^{\circ} \mathrm{C}$ for $2 \mathrm{hr}$ and then at $180^{\circ} \mathrm{C}$ for $24 \mathrm{hr}$ or $120 \mathrm{hr}$. The obtained sulfonated graft copolyimides were NTDA-APPF- $r$-DABA-gNTDA-BDSA-24 $\mathrm{hr}$ and NTDA-APPF- $r$-DABAg-NTDA-BDSA-120 hr, respectively. The block copolyimide main-chain polymer NTDA-APPF$b$-DABA was also individually added to the NTDA-BDSA solution to obtain NTDA-APPF$b$-DABA-g-NTDA-BDSA-24 hr and NTDAAPPF- $b$-DABA-g-NTDA-BDSA-120 hr, respectively. After cooling to room temperature, the solutions were poured into methanol several times to completely remove the residual sulfonated diamino-terminated polyimide, NTDA-BDSA. Then, the sulfonated graft copolyimides were precipitated in ethyl acetate. Finally, the sulfonated graft copolyimides were dried at $150^{\circ} \mathrm{C}$ under vacuum for $15 \mathrm{hr}$ to remove the residual solvents.

\subsection{Preparation of Sulfonated Graft Copolyimide Membranes}

The sulfonated graft copolyimide membranes were prepared using a solvent-cast method. The DMSO solution of the polyimide was cast on a glass plate, and the plate was then placed in a vacuum oven at $110^{\circ} \mathrm{C}$ for $24 \mathrm{hr}$. The membranes were immersed in ethanol and deionized water for $4 \mathrm{hr}$ each, then acidified with $0.1 \mathrm{M} \mathrm{HCl}$ solution for $4 \mathrm{hr}$, and finally washed with deionized water for $4 \mathrm{hr}$. The resulting membranes were dried in a vacuum oven at $80^{\circ} \mathrm{C}$ for $24 \mathrm{hr}$. The thickness of the each membrane was approximately $50 \mu \mathrm{m}$.

\subsection{Characterization of Sulfonated Graft CopolyimideMembranes}

The molecular weights $\left(M_{w}\right.$ and $\left.M_{n}\right)$ of NTDAAPPF- $r$-DABA and NTDA-APPF- $b$-DABA as the main-chain polymers and NTDA-BDSA as theside-chain polymer were determined by gelpermeation chromatography (detector: Jasco 830RI monitor, Tokyo, Japan) using two Shodex SB$806 \mathrm{HQ}$ and SB-804 HQ columns. $N, N-$ dimethylformamide containing $0.01 \mathrm{M}$ lithium bromide was used as the eluent at the flow rate of $1.0 \mathrm{~mL} / \mathrm{min}$. The molecular weights were estimated by comparing the retention times on the columns to those of polystyrene standard. The ion exchange capacity (IEC) was measured by classical titration using $\mathrm{NaOH}$ and $\mathrm{HCl}$ solutions. $^{10}$

The proton conductivity in the plane direction of the membrane was measured by electrochemical impedance spectroscopy over the frequency range from $50 \mathrm{~Hz}$ to $50 \mathrm{kHz}$ (Hioki 3532-50, Tolkyo, Japan) as reported in previous papers. ${ }^{10}$ The membranes $(1.0 \mathrm{~cm} \quad 3.0 \mathrm{~cm})$ and two blackened platinum plate electrodes were placed in a Teflon cell. The distance between the two electrodes was $1.0 \mathrm{~cm}$. The cell was placed in a temperature- and humidity-controlled chamber to measure the temperature and humidity dependence of the proton conductivity.

The water uptake of the sulfonated graft copolyimide membrane was gravimetrically measured from the dried and humidified membranes. ${ }^{17}$ The polyimide membrane was dried in a vacuum oven at $80^{\circ} \mathrm{C}$ for $10 \mathrm{hr}$ and then immersed in liquid water at room temperature. After $24 \mathrm{hr}$, the membrane was then wiped dry and quickly weighed. The water uptake was calculated using eq. (1)

$$
W=\frac{W_{s}-W_{d}}{W_{d}} \times 100 \%
$$

where $W_{\mathrm{s}}$ and $W_{\mathrm{d}}$ are the weights of the wet and dry membranes, respectively.

Size change in the sulfonated graft copolyimide membrane was measured in water at $80^{\circ} \mathrm{C}$ for 5 hr. The changes of the thickness and diameter were calculated from

$$
\Delta T=\frac{T_{s}-T_{d}}{T_{d}} \times 100(\%)
$$




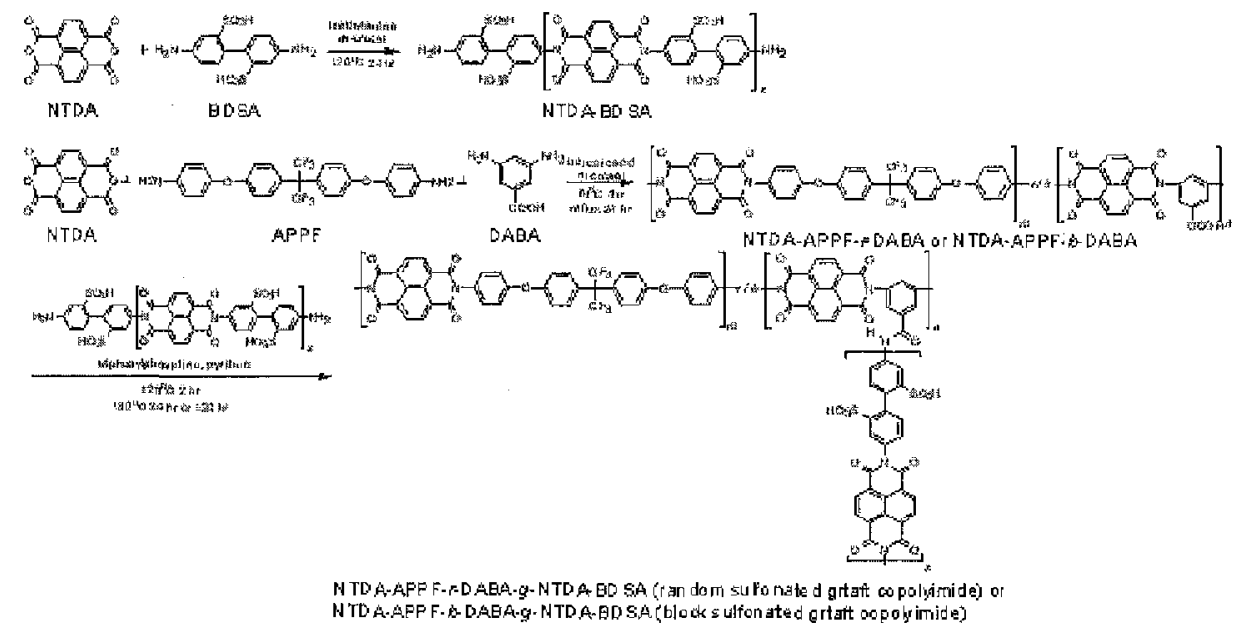

Scheme 1 Synthesis of NTDA-APPF-r-DABA- $g$-NTDA-BDSA and NTDA-APPF- $b$-DABAg-NTDA-BDSA

$$
\Delta L=\frac{\left(L_{s}-L_{d}\right)}{L_{d}} \times 100(\%)
$$

where $T_{s}$ and $L_{\mathrm{s}}$ are the thickness and diameter of the wet membranes, respectively, and $T_{d}$ and $L_{d}$ are the thickness and diameter of the dry membranes, respectively.

The oxidative stability to peroxide radical attack was investigated by measuring the elapsed times in which a membrane was completely dissolved after immersion of each membrane into Fenton's reagent of the $3 \% \mathrm{H}_{2} \mathrm{O}_{2}$ aqueous solution containing $2 \mathrm{ppm} \mathrm{FeSO}_{4}$ at $80^{\circ} \mathrm{C}$.

The gas permeability coefficients of oxygen, $P_{\mathrm{O} 2}$, was measured by a high vacuum apparatus (Rilka Seiki, Inc., K-315-H, Tokyo, Japan) ${ }^{23-25}$ The gas permeation measurements of the sulfonated copolyimide membranes were carried out from $25^{\circ} \mathrm{C}$ up to $45^{\circ} \mathrm{C}$ at $76 \mathrm{cmHg}$. The permeation parameters, $D$ and $S$, of the sulfonated copolyimide membranes were calculated from

$$
\begin{gathered}
P=D S \\
D=\frac{L^{2}}{6 \theta}
\end{gathered}
$$

using the time lag, $\theta$.

\subsection{RESULTS AND DISCUSSION}

\subsection{Synthesis of NTDA-APPF $-r / b$-DABA- g-NTDA-BDSA}

Scheme 1 shows the synthetic procedure of the novel sulfonated graft copolyimides in which the sulfonated polyimide chains were graftpolymerized to the random or block copolyimide main-chain polymer containing naphthalene moieties. Table 1 shows the IEC and grafting ratio of the sulfonated graft copolyimide. The grafting ratios were calculated from the measured IEC values, the theoretical IEC values of the side-chain polymer (NTDA-BDSA), and the molecular weights of the main-chain polymer (NTDA-APPF$r$-DABA or NTDA-APPF- $b$-DABA) and sidechain polymer (NTDA-BDSA). The IEC values of NTDA-APPF- $p / b$-DABA-g-NTDA-BDSA-120 $h$ were higher than those of NTDA-APPF-r/bDABA-g-NTDA-BDSA-24 $\mathrm{h}$ which means the grafting reaction proceeded more at longer grafting reaction time. Therefore, the sulfonated graft copolyimides with high grafting ratio possess higher molecular weights by grafting more sidechain sulfonated copolyimide into the main-chain polymer. By way of comparison, previously reported sulfonated graft copolyimides containing different polymer main-chain structures, $6 \mathrm{FDA}-$ HABA-g-NTDA-BDSA, ${ }^{19}$ bearing similar IECs 
Table 1 Ion exchange capacity (IEC) and grafting ratio of sulfonated graft copolyimides

\begin{tabular}{lcc}
\hline \multicolumn{1}{c}{ Polymer } & IEC(meq./g) & Grafting ratio (\%) \\
NTDA-APPF- $r$-DABA-g-NTDA-BDSA-24hr & 2.40 & 1.6 \\
NTDA-APPF- $r$-DABA-g-NTDA-BDSA-120hr & 3.15 & 17 \\
NTDA-APPF- $b$-DABA-g-NTDA-BDSA-24hr & 2.42 & 1.7 \\
NTDA-APPF- $b$-DABA-g-NTDA-BDSA-120hr & 3.17 & 19 \\
6FDA-HABA-g-NTDA-BDSA-24h & 2.43 & 1.5 \\
6FDA-HABA-g-NTDA-BDSA-120h & 3.14 & 14 \\
Nafion 117 & 0.91 & - \\
\hline
\end{tabular}

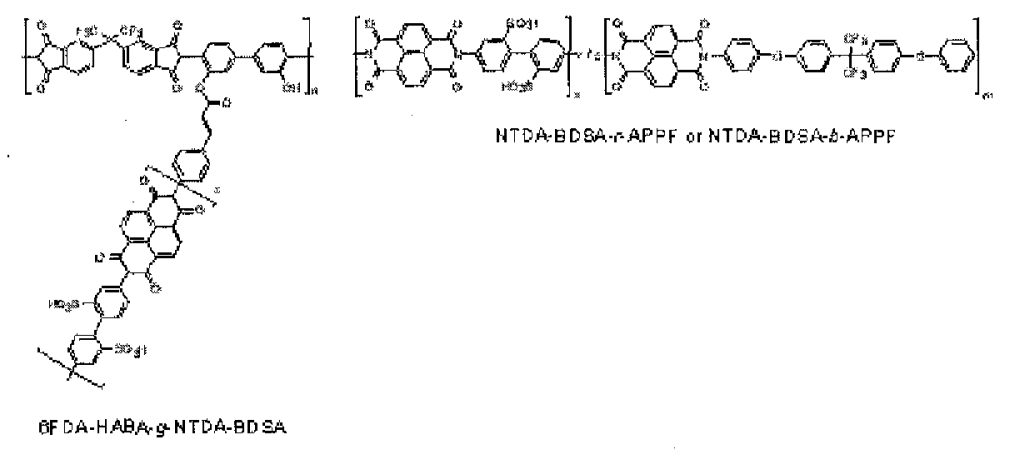

Figure 1 Chemical structures of 6FDA-HABA-g-NTDA-BDSA and NTDA-BDSA- $r / b-A P P F$

are shown in Figure 1 and Table 1. The chemical structures of liner-type sulfonated copolyimides, NTDA-BDSA-r-APPF and NTDA-BDSA- $b$ $A P P F,{ }^{18}$ are also shown in Figure 1. These are good references to compare the polymer mainchain effect on the characteristics of sulfonated graft copolyimides.

\subsection{Proton Conductivity and Water Uptake of NTDA-APPF-r/b-DABA-g-NTDA- BDSA}

Figure 2 shows the temperature dependence of the proton conductivity of the sulfonated graft copolyimide membranes at $98 \%$ relative humidity
(RH). The novel sulfonated graft copolyimides showed significantly high proton conductivity exceeding that of Nafion at all temperatures. The proton conductivities of NTDA-APPF- $b$-DABA$g$-NTDA-BDSA-120 $\mathrm{h}$ and NTDA-APPF- $r$ DABA-g-NTDA-BDSA- $24 \mathrm{~h}$ at $90^{\circ} \mathrm{C}$ and $98 \% \mathrm{RH}$ were 0.96 and $0.50 \mathrm{~S} / \mathrm{cm}$, which are 6.4 and 3.3 times higher than that of Nafion $(0.15 \mathrm{~S} / \mathrm{cm})$. It should be noted that NTDA-APPF-r-DABA-gNTDA-BDSA-24 $\mathrm{h}$ with an IEC value of 2.40 showed a significantly superior proton conductivity compared to that determined for other sulfonated aromatic hydrocarbon polymers as linear polymers with similar IECs. ${ }^{10-17}$ Among the sulfonated graft copolyimides, proton conductivities were dependent upon their IECs 


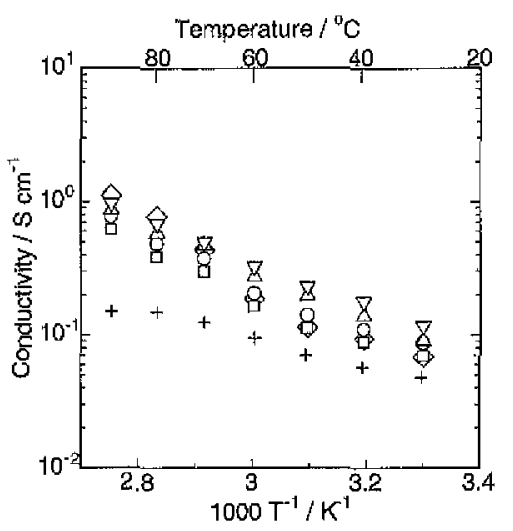

Figure 2 Temperature dependence of proton conductivity for sulfonated graft copolyimide membranes at $98 \% \mathrm{RH}$. : NTDA-APPF- $r$-DABA-g-NTDABDSA-24hr, $\Delta$ : NTDA-APPF- $r$-DABAg-NTDA-BDSA-120hr, $\square$ : NTDAAPPF-b-DABA-g-NTDA-BDSA-24hr, $\nabla:$ NTDA-APPF- $b$-DABA-g-NTDABDSA-120hr, $\vartheta:$ 6FDA-HABA-gNTDA-BDSA-24hr, + : Nafion 117

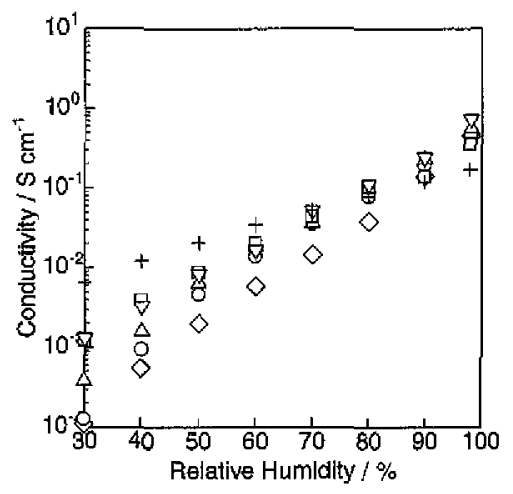

Figure 3 Relative humidity dependence of proton conductivity for sulfonated graft copolyimide membranes at $80^{\circ} \mathrm{C}$. $\circ$ : NTDA-APPF- $r$-DABA-g-NTDABDSA-24hr, $\triangle$ : NTDA-APPF- $r$-DABAg-NTDA-BDSA-120hr, $\square$ : NTDAAPPF- $b$-DABA-g-NTDA-BDSA-24hr, $\nabla:$ NTDA-APPF- $b$-DABA-g-NTDABDSA-120hr, $\diamond:$ 6FDA-HABA-gNTDA-BDSA-24hr, + : Nafion 117 and molecular structures. NTDA-APPF- $r / b-$ DABA-NTDA-BDSA-120 h shows higher proton conductivities than NTDA-APPF- $r / b$-DABANTDA-BDSA-24h because the sulfonated graft copolyimide prepared with longer grafting reaction time have higher IECs. In addition, the proton conductivity of the block copolyimide, NTDA-APPF- $b$-DABA-NTDA-BDSA- $120 \mathrm{~h}$, is higher than that of the corresponding random copolyimide, NTDA-APPF- $r$-DABA-NTDABDSA-120 h. On the other hand, NTDA-APPF$b$-DABA-NTDA-BDSA-24 h has lower conductivity than the corresponding random one. It is because the hydrophilic clusters, which form proton conductive channels, in NTDA-APPF- $b$ DABA-NTDA-BDSA-24 h may isolate because of its low grafting ratio and the block copolymer morphology. The reference copolyimide, 6FDAHABA-g-NTDA-BDSA, showed slightly higher conductivity than NTDA-APPF- $r$-DABA-NTDABDSA-24h at high temperatures, but the conductivity dropped with decreasing temperature to show lower conductivity than NTDA-APPF- $r$-DABA-NTDA-BDSA-24 $\mathrm{h}$ at below $60^{\circ} \mathrm{C}$. We found that the molecular structures and grafting ratio of the side-chain polymer in the sulfonated graft copolyimide had a significant influence on the proton conductivity of the sulfonated graft copolyimides.

Relative humidity dependence of the proton conductivity of sulfonated graft copolyimides are depicted in Figure 2. Though the novel sulfonated graft copolyimides showed higher proton conductivities than that of Nafion 117, the conductivities at lower relative humidity were lower than that of Nafion. The sulfonated graft copolyimides bearing block polymer main-chain structures showed relatively high conductivity even at low relative humidity because the block structures can easily form micro-phase separation to make better connection of the proton conductive channels. All NTDA-APPF- $r$-DABANTDA-BDSA membranes showed higher conductivities than 6FDA-HABA-g-NTDABDSA at all relative humidity. It is considered that the novel polymer main chain structures containing rigid naphthalene moieties could maintain better proton conductive channels in the membranes even at low humidity. 
The water uptake of the sulfonated graft copolyimides were summarized in Table 2 as well as the proton conductivities at $90^{\circ} \mathrm{C}$ and $98 \% \mathrm{RH}$. The water uptake of the sulfonated graft copolyimide membranes increased with increasing their IECs. In addition, the novel sulfonated graft copolyimides, NTDA-APPF- $r / b$ DABA-NTDA-BDSA, have slightly lower water uptake than those of 6FDA-HABA-g-NTDABDSA membranes. $r / b$-DABA-g-NTDA-BDSA have similar IECs, the oxidative stability of NTDA-APPF- $r$-DABA-gNTDA-BDSA-24 $h$ and NTDA-APPF- $b$-DABAg-NTDA-BDSA-24 $h$ exhibited 6 and 4 times larger values than that of 6FDA-HABA-g-NTDABDSA-24 h, respectively. It is considered that the sulfonic acid groups were only substituted at the side-chains to prevent from decomposition of the polymer main-chain along with elimination of the sulfonic acid groups by oxidative attacks. Besides, the polymer main-chain structure containing naphthalene di-imide, which is composed of high

Table 2 Water uptake and proton conductivity of sulfonated graft copolyimide membrane

\begin{tabular}{lccc}
\hline Polymer & IEC (meq./g) & Water uptake (\%) $^{\mathbf{a}}$ & Proton conductivity $^{\mathbf{b}}$ \\
\hline NTDA-APPF- $r$-DABA-g-NTDA-BDSA-24hr & 2.40 & 61 & \\
NTDA-APPF- $r$-DABA-g-NTDA-BDSA-120hr & 3.15 & 97 & 0.50 \\
NTDA-APPF- $b$-DABA-g-NTDA-BDSA-24hr & 2.42 & 59 & 0.85 \\
NTDA-APPF- $b$-DABA-g-NTDA-BDSA-120hr & 3.17 & 102 & 0.61 \\
6FDA-HABA-g-NTDA-BDSA-24h & 2.43 & 83 & 0.96 \\
6FDA-HABA-g-NTDA-BDSA-120h & 3.14 & 134 & 1.0 \\
Nafion 117 & 0.91 & 21 & 1.1 \\
\end{tabular}

at $25^{\circ} \mathrm{C}$ in water.

${ }^{b}$ at $90^{\circ} \mathrm{C}$ and $98 \% \mathrm{RH}$.

\subsection{Membrane Stability and Gas Permeability of NTDA-APPF- $r / b$ - DABA-g-NTDA-BDSA}

The polymer electrolyte membrane is required to have an excellent membrane stability and low gas permeability of the fuel and oxidant as well as high proton conductivity. In order to improve the membrane stability, there have been reported various approaches including cross-linking between polymers or hybridization of the membrane by the addition of inorganic particles. ${ }^{26,27}$ Polymer main-chain structures effect on their membrane stability as well as the crosslinking and additions. Table 3 shows the oxidative stability and dimensional change of sulfonated graft copolyimide membranes. Although the 6FDA-HABA-g-NTDA-BDSA and NTDA-APPF- stable condensed six-membered rings, in NTDAAPPF-r/b-DABA-g-NTDA-BDSA should affect to improve the oxidative stabilities. The dimensional changes of NTDA-APPF- $r / b$-DABA-g-NTDABDSA after immersing in hot water were almost similar to those of 6FDA-HABA-g-NTDA-BDSA. The low dimensional changes in plane direction of the NTDA-APPF- $r / b$-DABA-g-NTDA-BDSA membranes as well as the 6FDA-HABA-g-NTDABDSA membrane may help easier fuel cellassembly and longer-term cell operation. However, when compared to the perfluorosulfonated membranes, such as Nafion, the membrane stabilities of the novel sulfonated graft copolyimide membranes are also insufficient for use as fuel cell applications yet, and the more improvements of the membranes are required for fuel cell electrolytes. 
Table 3 Oxidative stability and dimensional change in sulfonated graft copolyimide

\begin{tabular}{|c|c|c|c|c|}
\hline Polymer & leq/g) & Oxidative stability $^{\text {a }}$ (h) & $\Delta T^{\mathrm{b}}(\%)$ & $\Delta L^{\mathrm{c}}(\%)$ \\
\hline NTDA-APPF- $r$-DABA-g-NTDA-BDSA-24hr & 2.40 & 3.0 & 104 & 7.0 \\
\hline NTDA-APPF- $r$-DABA-g-NTDA-BDSA-120hr & 3.15 & 2.0 & 99 & 6.0 \\
\hline NTDA-APPF- $b$-DABA-g-NTDA-BDSA-24hr & 2.42 & 2.0 & 106 & 8.0 \\
\hline NTDA-APPF- $b$-DABA-g-NTDA-BDSA-120hr & 3.17 & 1.5 & 108 & 9.0 \\
\hline 6FDA-HABA-g-NTDA-BDSA-24h & 2.43 & 0.5 & 88 & 4.8 \\
\hline 6FDA-HABA-g-NTDA-BDSA-120h & 3.14 & 0.5 & 95 & 6.0 \\
\hline Nafion 117 & 0.91 & - & 9 & 12 \\
\hline
\end{tabular}

a The oxidative stability was characterized by the time that the membranes completely dissolved in $3 \%$ $\mathrm{H}_{2} \mathrm{O}_{2}, 2$ ppm $\mathrm{FeSO}_{4}$ at $80^{\circ} \mathrm{C}$

${ }^{\mathrm{b}} \Delta T$ is the dimensional increase along thickness for a membrane immersed in water at $80^{\circ} \mathrm{C}$

${ }^{c} \Delta L$ is the dimensional increase in plane direction of a membrane immersed in water at $80^{\circ} \mathrm{C}$

Table 4 Oxygen permeability coefficient $\left(P_{\mathrm{O} 2}\right)$, diffusivity coefficient $\left(D_{\mathrm{O} 2}\right)$, and solubility coefficient $\left(S_{\mathrm{O} 2}\right)$ of sulfonated copolyimide membranes at $35^{\circ} \mathrm{C}$ and $76 \mathrm{~cm} \mathrm{Hg}$

\begin{tabular}{lccc}
\hline \multicolumn{1}{c}{ Polymer } & $\mathbf{P O}_{2}{ }^{\mathbf{a}}$ (Barrer) & $\mathbf{D O}_{2}{ }^{\mathbf{b}}$ & $\mathbf{S O}_{2}{ }^{\mathrm{c}}$ \\
\hline NTDA-APPF- $r$-DABA-g-NTDA-BDSA-24hr & 0.28 & 0.18 & 1.6 \\
NTDA-APPF-r-DABA-g-NTDA-BDSA-120hr & 0.21 & 0.15 & 1.4 \\
NTDA-APPF-b-DABA-g-NTDA-BDSA-24hr & 0.30 & 0.19 & 1.6 \\
NTDA-APPF- $b$-DABA-g-NTDA-BDSA-120hr & 0.24 & 0.17 & 1.4 \\
6FDA-HABA-g-NTDA-BDSA-24h & 0.35 & 0.21 & 1.7 \\
6FDA-HABA-g-NTDA-BDSA-120h & 0.14 & 0.12 & 1.2 \\
NTDA-BDSA & 0.31 & 0.21 & 1.5 \\
NTDA-BDSA- $r$-APPF & 1.0 & 0.72 & 1.4 \\
NTDA-BDSA- $b$-APPF & 1.2 & 0.89 & 1.3 \\
Nafion 117 & 1.1 & 4.6 & 0.23 \\
\hline
\end{tabular}

a $P \mathrm{O}_{2}: \operatorname{Barrer}\left(=10^{-10}\right)\left(\mathrm{cm}^{3}(\mathrm{STP}) \mathrm{cm} /\left(\mathrm{cm}^{2} \mathrm{sec} \mathrm{cmHg}\right)\right)$

${ }^{\mathrm{b}} \mathrm{DO}_{2}: 10^{-8}\left(\mathrm{~cm}^{2} / \mathrm{sec}\right)$

${ }^{c} \mathrm{SO}_{2}: 10^{-2}\left(\mathrm{~cm}^{3}(\mathrm{STP}) /\left(\mathrm{cm}^{3} \mathrm{cmHg}\right)\right)$

Meanwhile, gas permeability of polymer electrolyte membrane is also particularly important to prevent from the intermixture of feeding gases. Since it is generally known that high proton conductive membranes have relatively higher gas permeabilities, the basic idea for polymer electrolyte membranes to keep high proton conductivity while reducing the gas permeability is not necessarily definite. Table 4 shows the oxygen permeability coefficients of the sulfonated graft copolyimide membranes and the sulfonated block copolyimide membrane as control of the linear polymer in the dry state at $35^{\circ} \mathrm{C}$ and $76 \mathrm{cmHg}$. The oxygen permeability coefficients of NTDA-APPF- $r / b$-DABA-g-NTDABDSA membranes were 0.21-0.30 Barrer $\left(=10^{-}\right.$ 10) $\left[\mathrm{cm}^{3}(\mathrm{STP}) /\left(\mathrm{cm}^{2} \mathrm{sec} \mathrm{cmHg}\right)\right]$, which were approximately one-fourth that of Nafion $\left(P_{\mathrm{O} 2}=\right.$ 
1.1 $\left.\operatorname{Barrer}\left(=10^{-10}\right)\left[\mathrm{cm}^{3}(\mathrm{STP}) /\left(\mathrm{cm}^{2} \mathrm{sec} \mathrm{cmHg}\right)\right]\right)$. As oxygen permeability coefficients of the lineartype sulfonated copolyimide membranes, NTDABDSA-r-APPF (IEC $=2.1 \mathrm{meq} . / \mathrm{g}$, proton conductivity $=0.11 \mathrm{~S} / \mathrm{cm})$ and NTDA-BDSA- $b$ APPF $($ IEC $=2.1 \mathrm{meq} . / \mathrm{g}$, proton conductivity $=$ $0.42 \mathrm{~S} / \mathrm{cm})$, were 1.1 and $1.2 \operatorname{Barrer}\left(=10^{-10}\right)\left[\mathrm{cm}^{3}\right.$ (STP)/( $\mathrm{cm}^{2}$ sec cmHg)], respectively, ${ }^{18}$ the sulfonated graft copolyimide membranes were superior to the linear ones not only on their high proton conductivity but also on their low oxygen permeability. The low gas permeability of the sulfonated graft copolyimide membranes is responsible for the reduced diffusivity coefficient $\left(D_{\mathrm{O} 2}\right)$ as is apparent from Table 4 , and their $D_{\mathrm{O} 2}$ values were very similar to that measured in NTDA-BDSA as the side-chain polymer. In addition, high gas barrier characteristics are given in sulfonated graft copolyimides with higher grafting ratio (higher IEC) due to the remarkable reduction of the oxygen diffusivity. We consider that the strong intermolecular interaction induced by sulfonic acid groups suppresses the gas diffusivity through the sulfonated graft copolyimide membrane. On the other hand, the oxygen permeability for the NTDA-BDSA- $r / b$ APPF membrane as the linear-type polymer indicated high $D_{\mathrm{O} 2}$ values. It is necessary to measure the humidity dependence of the oxygen permeability coefficient for the sulfonated graft copolyimide membranes. In general, the gas permeability through a polymer membrane is known to increase with increasing humidity, and the oxygen permeability for the sulfonated graft copolyimide membranes also enhances with humidity. However, as reported by Watanabe, ${ }^{28}$ the increase ratio of the gas permeability coefficient for the sulfonated polyimide membrane under high humidity is almost similar to that measured in Nafion, therefore, we consider that the oxygen permeability coefficients of NTDAAPPF- $r / b$-DABA-g-NTDA-BDSA membranes significantly suppress when compared to that in Nafion.

\subsection{CONCLUSIONS}

A series of sulfonated graft copolyimides containing naphthalene moieties were successtully synthesized by controlling the grafting ratio between the non-sulfonated copolyimide as the main-chain polymer and the sulfonated copolyimide as the side-chain polymer. This paper revealed that the proton and oxygen transport properties of the sulfonated graft copolyimide membranes were dependent on the polymer structure and the grafting ratio. In particular, the sulfonated graft copolyimide, NTDA-APPF- $b$ DABA-g-NTDA-BDSA-120 hr, membrane showed higher proton conductivities exceeding that of Nafion at all temperatures, and its proton conductivities at $90^{\circ} \mathrm{C}$ and $98 \% \mathrm{RH}$ were $0.96 \mathrm{~S} /$ $\mathrm{cm}$, more than 6 times that of Nafion. The novel sulfonated graft copolyimides containing naphthalene di-imide moieties composed of sixmembered rings possessed higher oxidative stabilities than the previously reported sulfonated graft copolyimides bearing sulfonated polymer main-chain structure composed of five-membered rings. In addition, NTDA-APPF- $r / b$-DABA-gNTDA-BDSA membranes had excellent gas barrier properties, that is to say, oxygen permeabilities of the membranes was approximately one-fourth the value of Nafion due to their significantly low oxygen diffusivity. At this time, the NTDA-APPF- $b$-DABA-g-NTDABDSA-120 hr membrane was most desirable for proton exchange membranes, considering the balance among the proton conductivity, gas permeability, and membrane stability. In this study, we have proved that the sulfonated graft copolymer is a promising candidate for optimizing the polymer structure for fuel cell applications.

\section{ACIKNOWLEDGEMENT}

This worlk was supported by a grant from NEDO, Japan. 


\section{REFERENCES}

[1] Vielstich, W. 2009. Handbook of Fuel Cells. Chichester, England: Wiley.

[2] Steele, B. C. and H. A. Heinzel. 2001. Materials for Fuel-cell Technologies. Nature. 414: 345-352.

[3] Carrette, L., K. A. Friedrich, and U. Stimming. 2001. Fuel cells - Fundamentals and Applications. Fuel Cells. 1: 5-39.

[4] Borup, R., J. Meyers, B. Pivovar, Y.-S. Kim, R. Mukundan, N. Garland, D. Myers, M. Wilson, F. Garzon, D. Wood, P. Zelenay, K. More, K. Stroh, T. Zawodzinski, J. Boncella, J. E. McGrath, M. Inaba, K. Miyatake, M. Hori, K. Ota, Z. Ogumi, S. Miyata, A. Nishikata, Z. Siroma, Y. Uchimoto, K. Yasuda, K. Kimijima, and N. Iwashita. 2007. Scientific Aspects of Polymer Electrolyte Fuel Cell Durability and Degradation. Chem. Rev. 107: 3904-3951.

[5] Schuster, M., C. C. de Araujo, V. Atanasov, H. T. Andersen, K.-D. Kreuer, and J. Maier. 2009. Highly Sulfonated Poly (phenylene sulfone): Preparation and Stability Issues. Macromolecules. 42: 3129-3137.

[6] Qi, Y., Y. Gao, S. Tian, A. R. Hill, J. Gaudet, D. Guay, A. S. Hay. 2009. Synthesis and Properties of Novel BenzimidazoleContaining Sulfonated Polyethersulfones for Fuel Cell Applications. J. Polym. Sci. Polym. Chem. 47: 1920-1929

[7] Lee, H.-S., O. Lane, and J. E. McGrath. 2010. Development of Multiblock Copolymers with Novel Hydroquinone-based Hydrophilic Blocks for Proton Exchange Membrane (PEM) Applications. J. Power Sources. 195: 1772-1778.

[8] Saito, T., H. D. Moore, and M. A. Hickner. 2010. Synthesis of Midblock-sulfonated Triblock Copolymers. Macromolecules 43: 599-601.

[9] Bae, B., T. Yoda, K. Miyatake, H. Uchida, and $M$. Watanabe. 2010. Proton-conductive Aromatic Ionomers Containing Highly Sulfonated Blocks for High-temperatureoperable Fuel Cells. Angew. Chem. Int. Ed. 49: 317-320.

[10] Nakano, T., S. Nagaoka, H. Kawakami.
2005. Preparation of Novel Sulfonated Block Copolyimides for Proton Conductivity Membranes. Polym. Adv. Technol. 16: 753-757.

[11] Jang, W., C. Lee, S. Sundar, Y. G. Shul, and H. Han. 2005. Thermal and Hydrolytic Stability of Sulfonated Polyimide Membranes with Varying Chemical Structure. Polym. Degrad. Stab. 90: 431440.

[12] Rao, X., H. Zhou, G. Dang, C. Chen, and Z. Wu. 2006. New Kinds of PhenylethynylTerminated Polyimide Oligomers with Low Viscosity and Good Hydrolytic Stability. Polymer. 47: 6091-6098.

[13] Lee, C. H., Park, H. B. Chung, Y. S., Lee, Y. M., Freeman, B. D. 2006. Water Sorption, Proton Conduction, and Methanol Permeation Properties of Sulfonated Polyimide Membranes Cross-linked with $\mathrm{N}, \mathrm{N}$ - b is (2-hydroxyet hy 1$)-2$ aminoethanesulfonic Acid (BES). Macromolecules. 39: 755-764.

[14] Okazaki, Y., S. Nagaoka, and H. Kawakami. 2007. Proton-conductive Membranes based on Blends of Polyimides. J. Polym. Sci. Polym. Phys. 45: 1325-1332.

[15] Li, N., S. Zhang, J. Liu, and F. Zhang. 2008. Synthesis and Properties of Sulfonated Poly [bis(benzimidazobenzisoquinolinones)] as Hydrolytically and Thermooxidatively Stable Proton Conducting Ionomers. Macromolecules. 41: 4165-4172.

[16] Saito, J., M. Tanaka, K. Miyatake, and M. Watanabe. 2010. Proton Conductive Polyimide Ionomer Membranes: Effect of $\mathrm{NH}, \mathrm{OH}$, and COOH Groups. J. Polym. Sci. Polym. Chem. 48: 2846-2854.

[17] Suda, T., K. Yamazaki, H. Kawakami. 2010. J. Power Sources. 195: 4641-4646.

[18] Yamazaki, K., Y. Tang, and H. Kawakami. 2010. Proton Conductivity and Stability of low-IEC Sulfonated Block Copolyimide Membrane. J. Memb. Sci. 362: 234-240.

[19] Yamazaki, K. and H. Kawakami. 2010. High Proton Conductive and Low Gas Permeable Sulfonated Graft Copolyimide Membrane. Macromolecules. 43: 7185-7191:

[20] Liu, F, B. Yi, D. Xing, J. Yu, and H. Zhang. 
2003. Nafion/PTFE Composite Membranes for Fuel Cell Applications. J. Membr. Sci. 212: 213-223.

[21] Cheng, X., J. Zhang, Y. Tang, C. Song, J. Shen, D. Song, and J. Zhang. 2007. Hydrogen Crossover in High-temperature PEM Fuel Cells. J. Power Sources. 167: 2531.

[22] Inaba, M., T. Kinumoto, M. Kiriake, R. Umebayashi, A. Tasaka, and Z. Ogumi. 2009. Durability of a Novel Sulfonated Polyimide Membrane in Polymer Electrolyte Fuel Cell Operation. Electrochim. Acta. 54: 1076-1082.

[23] Mikawa, M., S. Nagaoka, and H. Kawakami. 1999. Asymptotic Behaviour in the Pressure-driven Separations of Ions of Different Mobilities in Charged Porous Membranes. J. Membr. Sci. 163: 167-185.

[24] Sannomiya, A., S. Nagaoka, Y. Suzuki, M. Iwaki, and H. Kawakami. 2006. Gas Diffusion and Solubility in $\mathrm{He}+$-irradiated
Asymmetric Polyimide Membranes. Polymer. 47; 6585-6591.

[25] Kawakami, H., K. Nakajima, and S. Nagaoka. 2003. Gas Separation Characteristics of Isomeric Polyimide Membrane Prepared under Shear Stress. J. Membr. Sci. 211: 291-298.

[26] Lee, C. H., S. Y. Hwang, J. Y. Sohn, H. B. Park, J. Y. Kim, and Y. M. Lee. 2006. WaterStable Crosslinked Sulfonated Polyimidesilica Nanocomposite Containing Interpenetrating Polymer Network. $J$. Power Sources. 163: 339-348.

[27] Lee, K.-S., M.-H. Jeong, J.-P.Lee, and J.S.Lee. 2009. End-group Cross-linked Poly(arylene ether) for Proton Exchange Membranes. Macromolecules. 42: 584-590.

[28] Saito, J., K. Miyatake, and M. Watanabe. 2008. Synthesis and Properties of Polyimide Ionomers Containing $1 \mathrm{H}-1,2,4-$ Triazole Groups. Macromolecules. 41: 2415-2420. 